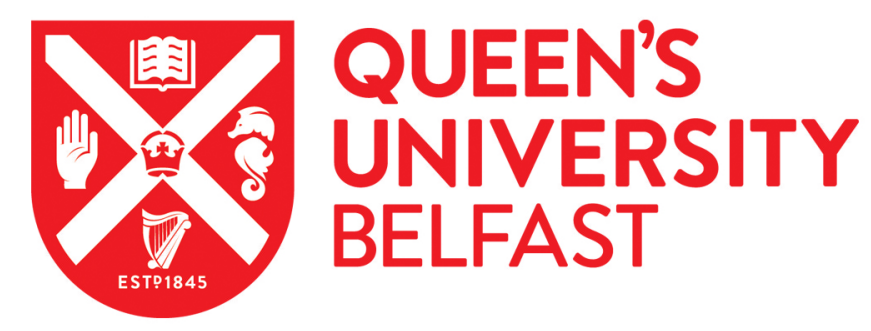

\title{
Electron paramagnetic resonance studies of nitrogen interstitial defects in diamond
}

Felton, S., Cann, B. L., Edmonds, A. M., Liggins, S., Cruddace, R. J., Newton, M. E., Fisher, D., \& Baker, J. M. (2009). Electron paramagnetic resonance studies of nitrogen interstitial defects in diamond. Journal of Physics: Condensed Matter, 21(36), [364212]. https://doi.org/10.1088/0953-8984/21/36/364212

Published in:

Journal of Physics: Condensed Matter

Document Version:

Peer reviewed version

Queen's University Belfast - Research Portal:

Link to publication record in Queen's University Belfast Research Portal

\section{Publisher rights}

(C) Copyright 2016 IOP Publishing

This is an author-created, un-copyedited version of an article

accepted for publication in Journal of Physics: Condensed Matter. The publisher is not responsible for any errors or omissions in this version of the

manuscript or any version derived from it. The Version of Record is

available online at http://iopscience.iop.org/article/10.1088/0953-8984/21/36/364212/meta

General rights

Copyright for the publications made accessible via the Queen's University Belfast Research Portal is retained by the author(s) and / or other copyright owners and it is a condition of accessing these publications that users recognise and abide by the legal requirements associated with these rights.

Take down policy

The Research Portal is Queen's institutional repository that provides access to Queen's research output. Every effort has been made to ensure that content in the Research Portal does not infringe any person's rights, or applicable UK laws. If you discover content in the Research Portal that you believe breaches copyright or violates any law, please contact openaccess@qub.ac.uk. 


\title{
EPR studies of nitrogen interstitial defects in diamond
}

\author{
S Felton ${ }^{1}$, B L Cann ${ }^{1}$, A M Edmonds ${ }^{1}$, S Liggins ${ }^{1}$, R J \\ Cruddace $^{1}$, M E Newton ${ }^{1}$, D Fisher ${ }^{2}$ and J M Baker ${ }^{3}$ \\ ${ }^{1}$ Department of Physics, University of Warwick, Coventry, CV4 7AL, U.K. \\ E-mail: m.e.newton@warwick.ac.uk \\ ${ }^{2}$ De Beers Research Group, Belmont Road, Maidenhead, Berkshire, SL6 6JW, U.K. \\ ${ }^{3}$ Oxford Physics, Clarendon Laboratory, Oxford, OX1 3PU, U.K.
}

\begin{abstract}
We report on electron paramagnetic resonance studies of nitrogen-doped diamond that has been ${ }^{15} \mathrm{~N}$-enriched, electron-irradiated and annealed. EPR spectra from two new nitrogen containing $S=\frac{1}{2}$ defects are detected and labelled WAR9 and WAR10. We show that the properties of these defect are consistent with them being the $\langle 001\rangle$-nitrogen split interstitial and the $\langle 001\rangle$-nitrogen split interstitial- $\langle 001\rangle$ carbon split interstitial pair, respectively. We also provide an explanation for why these defects have previously eluded discovery.
\end{abstract}

PACS numbers: 81.05.Uw, 61.72.jn, 76.30.Mi

Submitted to: J. Phys.: Condens. Matter

\section{Introduction}

Isolated vacancies and self interstitials are produced by the irradiation of diamond with particles of sufficient energy to displace carbon atoms. The production of primary and secondary irradiation damage defects has been intensively studied in intrinsic diamond. The neutral $\left(\mathrm{V}^{0}\right)$ and negatively $\left(\mathrm{V}^{-}\right)$charged isolated vacancy have been thoroughly characterised by optical $[1,2,3,4,5]$ and EPR spectroscopy [6, 7], and experiment and theory are in good accord. The activation energy for migration of $\mathrm{V}^{0}$ is $2.2 \mathrm{eV}$ [8], and in intrinsic diamond substantial concentrations of di-vacancies can be produced by annealing at $1100 \mathrm{~K}$ [9]. There is no evidence for excitation enhanced migration of the vacancy [10], however the situation is far more complicated for the interstitial. Theoretically the $\langle 001\rangle$-split-self-interstitial $\left(\mathrm{I}_{001}\right)$ is by far the lowest energy configuration [11], and this is the only one observed and characterised by EPR [10] and optical spectroscopy [12]. For $1-2 \mathrm{MeV}$ electron irradiation at $\sim 100 \mathrm{~K}$ the production of isolated vacancies and interstitials is identical [10]. However as the temperature is increased excitation enhanced migration of the interstitial with an activation energy of 
$\sim 0.3 \mathrm{eV}$ has been observed [13]. It is uncertain as to whether this enhanced mobility is due to electronic excitation of the neutral $\mathrm{I}_{001}$ defect or is characteristic of e.g. $\mathrm{I}_{001}^{-}$. This result explains the production of di-interstitial aggregates upon room temperature irradiation [14], whereas post irradiation annealing shows that the activation energy for migration of $\mathrm{I}_{001}$ is $1.6 \mathrm{eV}[13,15]$. Following annealing above the migration temperature of $\mathrm{I}_{001}$ a three interstitial aggregate has been observed by EPR [16] and a diamagnetic four interstitial aggregate predicted by theory [11].

Nitrogen is a common impurity in both natural and synthetic diamond and it is used as the basis for classifying diamond [17]: Type I diamond contains significant quantities of nitrogen as measured by Infra-red (IR) absorption; Type II diamond does not. Type I diamond is further subdivided into Type Ia, in which the nitrogen is present in aggregated forms, and Type Ib, containing mostly single substitutional nitrogen, $\mathrm{N}_{\mathrm{S}}$. Common forms of aggregated nitrogen in diamond are two nearest-neighbour substitutional nitrogen atoms, known as the A-centre, four substitutional nitrogen atoms surrounding a vacant lattice site (vacancy), called the B-centre, and three substitutional nitrogen atoms next to a vacancy, labelled N3 [17].

Much is known of the interaction of vacancies with nitrogen impurities. Charge transfer from the neutral single substitutional nitrogen $\left(\mathrm{N}_{\mathrm{S}}^{0}\right)$ donor produces $\mathrm{V}^{-}$

$$
\mathrm{V}^{0}+\mathrm{N}_{\mathrm{S}}^{0} \rightleftarrows \mathrm{V}^{-}+\mathrm{N}_{\mathrm{S}}^{+} \text {. }
$$

Upon annealing above $\sim 900 \mathrm{~K}$ the stationary $\mathrm{N}_{\mathrm{S}}$ readily traps vacancies to produce nitrogen vacancy complexes

$$
\begin{aligned}
& \mathrm{N}_{\mathrm{S}}^{0}+\mathrm{V} \rightarrow \mathrm{NV}^{0} \\
& \mathrm{NV}^{0}+\mathrm{N}_{\mathrm{S}}^{0} \rightarrow \mathrm{NV}^{-}+\mathrm{N}_{\mathrm{S}}^{+}
\end{aligned}
$$

and both the neutral and negatively charged NV-centres are discussed extensively elsewhere $[8,18,19]$. Substitutional nitrogen pairs (A-centres) also trap mobile vacancies (although less efficiently than $\mathrm{N}_{\mathrm{S}}$ ) to produce $\mathrm{N}-\mathrm{V}-\mathrm{N}$ defects [8]; again neutral (H3) and negatively charged (H2) versions are produced [20, 21, 22, 23]. The NV centre anneals out at $\sim 1800 \mathrm{~K}$, with the associated production of A-centres via vacancyassisted aggregation

$$
\begin{aligned}
& \mathrm{NV}+\mathrm{N}_{\mathrm{S}} \rightarrow \mathrm{N}_{\mathrm{S}}-\mathrm{N}_{\mathrm{S}}+\mathrm{V} \\
& \mathrm{N}_{\mathrm{S}}+\mathrm{V} \rightarrow \mathrm{NV} \\
& \text { etc }
\end{aligned}
$$

[24]. High temperature annealing (under stabilising pressures) of nitrogen containing diamond usually results in specimens with detectable (at least by photoluminescence) concentrations of $\mathrm{NV}^{0 /-}$ and $\mathrm{NVN}^{0 /-}$, which have been 'quenched' in, but this will not be discussed further here [23, 25].

Our understanding of the fate of interstitials in nitrogen doped diamond is far less advanced. We know that (R1) di-interstitials are not produced in diamond doped with $\mathrm{N}_{\mathrm{S}}$ when the concentration of nitrogen greatly exceeds that of the interstitials produced 
by irradiation damage [26]. The production of isolated $\mathrm{I}_{001}^{0}$ interstitials was not altered by the presence of $\mathrm{N}_{\mathrm{S}}^{0}[26]$, indicating that even with the deep donor present the neutral charge state of $\mathrm{I}_{001}$ is preferred. Once mobile we postulate that the $\mathrm{I}_{001}$ interstitials are trapped by $\mathrm{N}_{\mathrm{S}}^{0}$ producing $\mathrm{N}_{\mathrm{I}}$

$$
\mathrm{I}_{001}+\mathrm{N}_{\mathrm{S}}^{0} \rightarrow \mathrm{N}_{\mathrm{I}}
$$

where one of the atoms of the interstitial dumbbell is replaced by the nitrogen atom. It is unlikely that $\mathrm{N}_{\mathrm{I}}$ would dissociate but migrate as a unit [27], once mobile. Goss et al. [27] predicted that the barrier to migration for $\mathrm{N}_{\mathrm{I}}^{-}$is substantially less than that for $\mathrm{N}_{\mathrm{I}}^{0}$. The capture of $\mathrm{I}_{001}$ by $\mathrm{N}_{\mathrm{I}}$ would produce an $\mathrm{R} 1$ like di-interstitial with one of the three-fold coordinated carbons replaced with a nitrogen $\left(\left[\mathrm{N}_{\mathrm{I}}-\mathrm{I}_{001}\right]\right)$. Capture of $\mathrm{N}_{\mathrm{I}}$ by $\mathrm{N}_{\mathrm{S}}$ would produce $\mathrm{N}_{2 \mathrm{I}}$ where both dumbbell atoms of the interstitial are replaced by nitrogens. Goss et al. [27] proposed that this defect was responsible for the H1a local vibrational mode [28]. In the neutral charge state both $\mathrm{N}_{\mathrm{I}}$ and $\mathrm{N}_{\mathrm{I}}-\mathrm{I}_{001}$ would be paramagnetic and should be observable by EPR if not obscured by other defects; the detection of both is the subject of this paper.

We can postulate further that in diamond where the nitrogen is incorporated as Acentres mobile interstitials will be trapped by A-centres to produce $\mathrm{N}_{2 \mathrm{I}}$ directly. Indeed this was the argument put forward by Goss et al. to explain the different temperatures at which H1a is annealed into type Ib and type Ia diamond [27].

It has been shown that incorporation of nitrogen in HPHT diamond is growth sector dependent, with $\{111\}$ sectors typically showing the highest $\mathrm{N}_{\mathrm{S}}$ concentration [29]. Burns et al. [29] found that in a sample where the $\{111\}$ sectors contained $\sim 100 \mathrm{ppm}$ (atomic parts per million) $\mathrm{N}_{\mathrm{S}}^{0}$ the $\{100\}$ sectors contained $\sim 50 \mathrm{ppm} \mathrm{N}_{\mathrm{S}}^{0}$ with the $\{113\}$ and $\{110\}$ sectors containing substantially less $\mathrm{N}_{\mathrm{S}}^{0}$ at $\sim 10 \mathrm{ppm}$ and $\sim 1$ ppm, respectively. Thus following irradiation, it is important to bear in mind that we have to consider both the situations where $\left[\mathrm{N}_{\mathrm{S}}^{0}\right] \gg\left[\mathrm{V}\left[,\left[\mathrm{I}_{001}\right]\right.\right.$ and $\left[\mathrm{N}_{\mathrm{S}}^{0}\right] \ll[\mathrm{V}],\left[\mathrm{I}_{001}\right]$ in a mixed growth sector sample. In the former we are likely to produce diamagnetic $\mathrm{N}_{\mathrm{I}}^{-}$and $\left[\mathrm{N}_{\mathrm{I}}-\mathrm{I}_{001}\right]^{-}$, in the latter paramagnetic $\mathrm{N}_{\mathrm{I}}^{0}$ and $\left[\mathrm{N}_{\mathrm{I}}-\mathrm{I}_{001}\right]^{0}$ when interstitials are mobile. Following the work by Goss et al. [27] on the mobilities of $\mathrm{N}_{\mathrm{I}}^{0}$ and $\mathrm{N}_{\mathrm{I}}^{-}$we might expect different concentrations of the defects in the different growth sectors. We have to consider carefully the consequences of different mobilities and stabilities in the two charge states.

\section{Experimental}

The sample used in this study is a synthetic mixed type IaA/Ib diamond. It was grown using a modified high pressure, high temperature (HPHT) synthesis method [30]: Atmospheric gases were removed from the growth capsule containing the solvent/catalyst and carbon source by heating it in vacuum. At a lower temperature, the removed gases were replaced with ${ }^{15} \mathrm{~N}$ enriched gases. The growth capsule was then sealed and the pre-treated reaction mixture was subjected to HPHT conditions 
in the diamond stable region. This produced a type Ib material, where $>95 \%$ of the nitrogen was ${ }^{15} \mathrm{~N}$, with a mean bulk concentration of approximately $150 \mathrm{ppm} \mathrm{N}_{\mathrm{S}}^{0}[30]$. The sample is made up of several different growth sectors. Through HPHT annealing $>80 \%$ of the $\mathrm{N}_{\mathrm{S}}$ in the high concentration sectors was aggregated to A-centres, making these sectors mixed type IaA, with an A-centre concentration of $\sim 60 \mathrm{ppm}$ and an $\mathrm{N}_{\mathrm{S}}^{0}$ concentration of $\sim 30 \mathrm{ppm}$. In the sectors with low nitrogen concentration, little or no aggregation is likely to have occurred: if we assume that the low nitrogen sectors have a concentration of $1 \mathrm{ppm} \mathrm{N}_{\mathrm{S}}^{0}$ annealing at a temperature of $2300 \mathrm{~K}$ would only yield a 1\% aggregation to A-centres, while the same annealing temperature would lead to $\sim 80 \%$ aggregation to A-centres in sectors with $150 \mathrm{ppm} \mathrm{N}_{\mathrm{S}}^{0}[31,32]$. After the HPHTannealing the sample was irradiated with $1.5 \mathrm{MeV} \mathrm{e}^{-}$to a dose of $4 \times 10^{17}$ electrons $/ \mathrm{cm}^{2}$ at room temperature leading to a vacancy $\left(\mathrm{V}^{0}\right.$ and $\left.\mathrm{V}^{-}\right)$concentration of $\sim 3 \mathrm{ppm}[10]$. The mean bulk concentration of $\mathrm{V}^{-}$was determined from the EPR spectra recorded post-irradiation, figure $1 \mathrm{~b}$ ), to be $\sim 1 \mathrm{ppm}$. The sample was subsequently annealed for 4 hours at $1100 \mathrm{~K}$ in an non-oxidising atmosphere, to create secondary irradiation defects such as NV-centres and possibly nitrogen-interstitial defects such as $\mathrm{N}_{\mathrm{I}}, \mathrm{N}_{2 \mathrm{I}}$ etc. The annealing time and temperature were chosen to remove all isolated vacancies [8].

Room temperature EPR spectra for the sample were collected using a Bruker EMX continuous wave X-band spectrometer with an operating frequency of $\sim 9.75 \mathrm{GHz}$ and a custom-built Q-band spectrometer, which has been described elsewhere by Twitchen et al. [14]. An Oxford Instruments Liquid Helium ESR900 flow cryostat was used with the Bruker EMX X-band spectrometer to perform measurements at cryogenic temperatures.

The presence of sectors with different defect concentrations in the sample is confirmed by the EPR spectra, see e.g. figure 1a), where it can be clearly seen that the $\mathrm{N}_{\mathrm{S}}^{0}$ EPR spectrum is made up of signals with components of different line widths [33]. For a nitrogen defect concentration of the order of $10 \mathrm{ppm}$ or above the EPR line width increases roughly linearly with the defect concentration; for concentrations below $10 \mathrm{ppm}$ the line width is determined by the interaction with the ${ }^{13} \mathrm{C}$ present at natural abundance of $1.1 \%$ in the sample [33]. From this we can conclude that there are regions in the studied sample with defect concentrations below $10 \mathrm{ppm}$ and other regions with defect concentrations up to an order of magnitude larger. As discussed in section 1 the $\{110\}$ sectors may contain as little as $1 \mathrm{ppm}$ of $\mathrm{N}_{\mathrm{S}}^{0}$. Consequently there is likely to have been regions of the sample where the vacancy concentration was roughly equal to the concentration of $\mathrm{N}_{\mathrm{S}}$. If $\left[\mathrm{N}_{\mathrm{S}}^{0}\right] \leq[\mathrm{V}]$ in the low nitrogen sectors $\mathrm{V}^{0}+\mathrm{N}_{\mathrm{S}}^{0} \rightarrow \mathrm{V}^{-}+\mathrm{N}_{\mathrm{S}}^{+}$so that in these sectors almost all of the $\mathrm{N}_{\mathrm{S}}$ is present as diamagnetic $\mathrm{N}_{\mathrm{S}}^{+}$. This assumption is supported by figure $1 \mathrm{~b}$ ), where the narrow component of the $\mathrm{N}_{\mathrm{S}}^{0}$ EPR spectrum is dramatically reduced compared to figure 1a).

Figure 1b) shows an EPR spectrum of the sample post-irradiation, where the large signal in the centre of the spectrum is from the negatively charged vacancy [6]. This is the region of the spectrum where the lines from the new defects appear, so that even if they were present in the sample post-irradiation but pre-annealing, they would not be detectable due to overlap with the negative vacancy signal. 

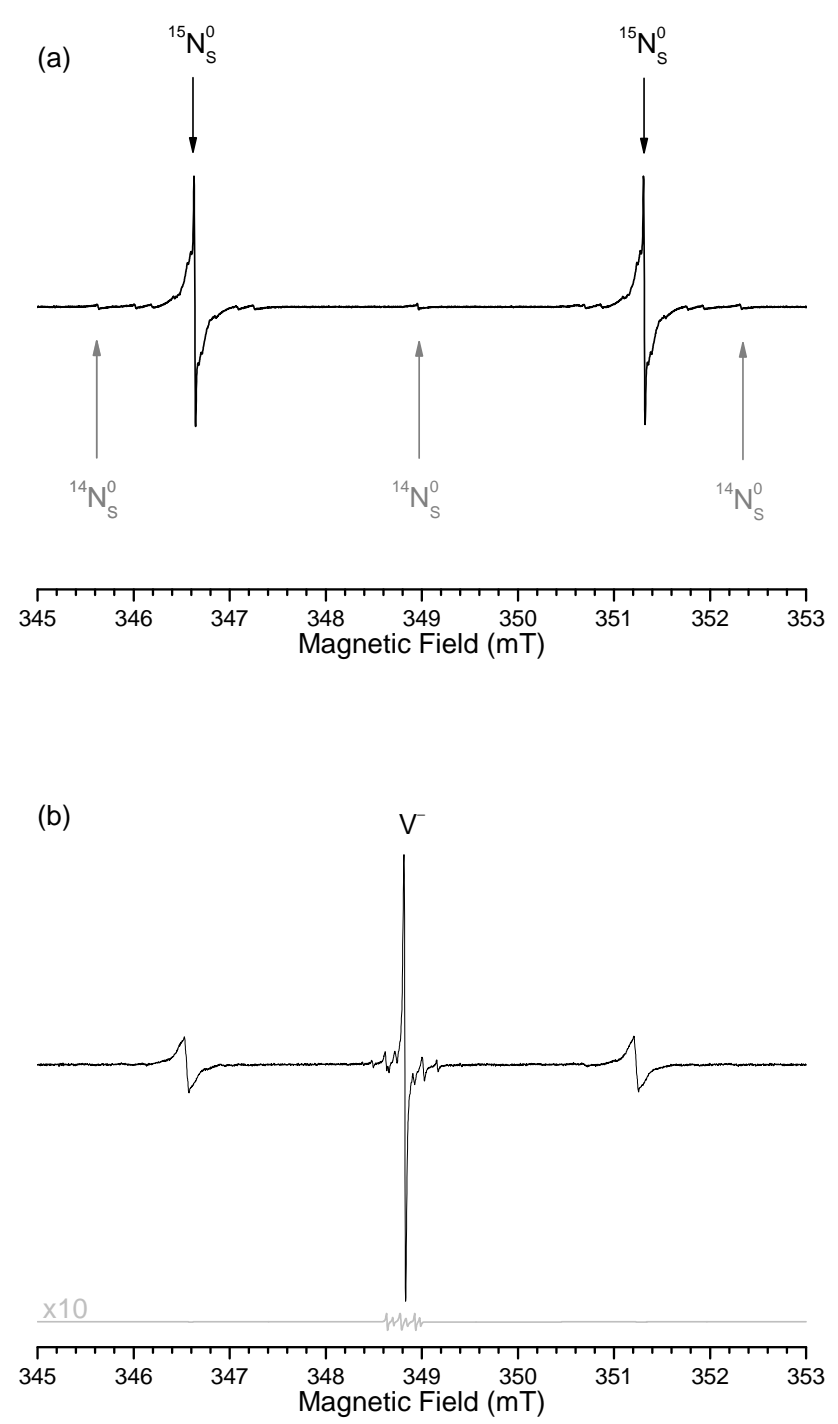

Figure 1. X-band first derivative EPR spectra (black line) recorded with the magnetic field applied along $\langle 001\rangle$ for the sample a) post-HPHT treatment but pre-irradiation and b) post-irradiation. Note that the ${ }^{15} \mathrm{~N}_{\mathrm{S}}^{0} \mathrm{EPR}$ spectrum, marked with black arrows in figure a), is made up of components with different line-widths due to variation in concentrations of defects in different sectors of the sample. The much less intense lines of the ${ }^{14} \mathrm{~N}_{\mathrm{S}}^{0}$ EPR spectrum are marked with grey arrows in figure a). In figure b) note the large signal, with ${ }^{13} \mathrm{C}$ satellites, in the middle of the spectrum from the negatively charged vacancies present in the sample post-irradiation. For comparison, simulated spectra of the two new defects (grey line) are shown below the experimental spectrum, at approximately ten times the signal intensity expected from the concentration detected post-annealing. The vertical scale in figure a) is half that of figure b). Note that the narrow component of the $\mathrm{N}_{\mathrm{S}}^{0} \mathrm{EPR}$ spectrum is dramatically diminished in figure b) compared to figure a). This is attributed to almost complete charge transfer from $\mathrm{N}_{\mathrm{S}}$ to $\mathrm{V}$ in the low nitrogen sectors, see text for details. 


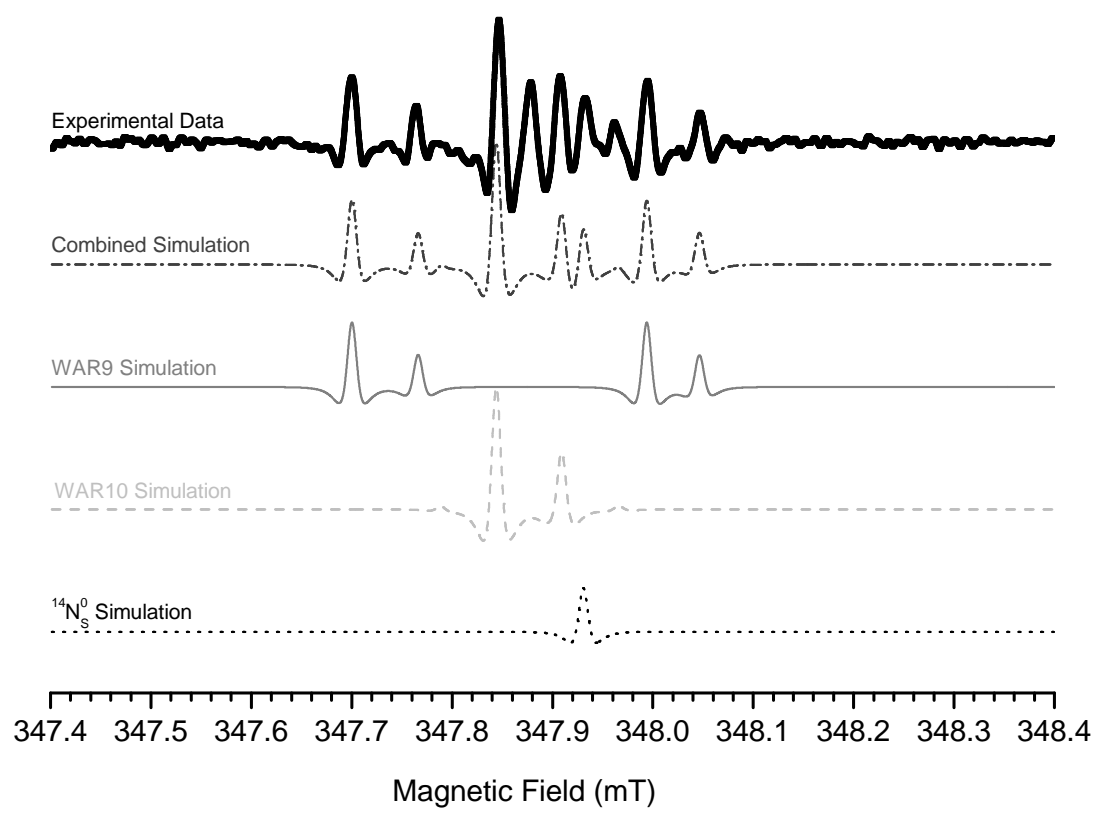

Figure 2. X-band second derivative experimental (thick black line) and simulated spectra at $\mathrm{f}=9.752 \mathrm{GHz}$ with the magnetic field applied along $\langle 001\rangle$. The solid grey line (- ) shows the simulated WAR9 spectrum, the dashed grey line (- - - ) shows the simulated WAR10 spectrum, and the dotted black line $(\cdots \cdots)$ shows the ${ }^{14} \mathrm{~N}_{\mathrm{S}}^{0}$ spectrum. This line is used as a $g$-marker and the electronic Zeeman parameters of table 1 are referenced to the g-value 2.0024 of $\mathrm{N}_{\mathrm{S}}^{0}$. [34] The grey dash-dotted line $(-\cdot-)$ shows the sum of all the simulated spectra.

\section{Results}

EPR measurements post irradiation and annealing revealed spectra from two previously unreported defects, labelled WAR9 and WAR10, each showing hyperfine interaction with one $\sim 100 \%$ abundant $I=\frac{1}{2}$ nucleus, see figure 2 and 3 . The EPR spectra for the new defects both have line widths of $0.02 \mathrm{mT}$, like the narrow component of the $\mathrm{N}_{\mathrm{S}}^{0}$ spectrum. From the integrated intensity of the EPR signal of the WAR9 and WAR10 spectra the mean bulk concentration of these defects were found to be 0.10(1) ppm (atomic parts per million) each. In the same way the ${ }^{15} \mathrm{~N}_{\mathrm{S}}^{0}$ and ${ }^{14} \mathrm{~N}_{\mathrm{S}}^{0}$ mean bulk concentrations were determined to be $20(2) \mathrm{ppm}$ and $0.72(7) \mathrm{ppm}$, respectively. The sample also contains 0.6(1) $\mathrm{ppm}$ of $\mathrm{NV}^{-}$.

$\mathrm{X}$-band EPR roadmaps for the new defects were produced by recording spectra with the magnetic field applied at $5^{\circ}$ increments in a $\{110\}$ crystallographic plane, see figure 5. Q-band EPR spectra were recorded with the magnetic field applied along the three principal directions $\langle 001\rangle,\langle 110\rangle$ and $\langle 111\rangle$, as well as two intermediate directions in a $\{110\}$ plane, see figure 6 . The orientation of the applied magnetic field, $\mathbf{B}$, with 

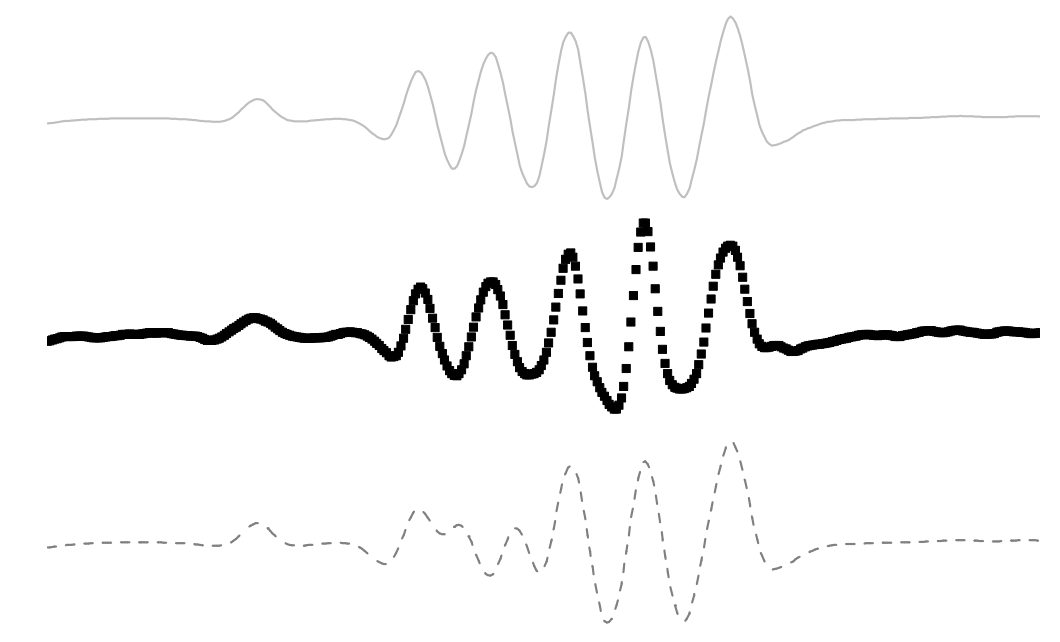

1247.41247 .61247 .81248 .01248 .21248 .41248 .61248 .81249 .01249 .21249 .4

Magnetic Field (mT)

Figure 3. Q-band second derivative experimental ( $\mathbf{m})$ and simulated spectra at $\mathrm{f}=35 \mathrm{GHz}$ for WAR9, WAR10 and ${ }^{14} \mathrm{~N}_{\mathrm{S}}^{0}$ with the magnetic field applied along $\langle 111\rangle$. The upper solid grey line $(-)$ shows a simulation using the WAR10 parameters from table 1 and the lower dashed grey line (- - -) shows a simulation using a spin Hamiltonian with lower g-symmetry and no hyperfine interaction for WAR10, which fits the X-band data. The parameters for WAR9 and ${ }^{14} \mathrm{~N}_{\mathrm{S}}^{0}$ are the same for both simulations. Only the simulation including a hyperfine interaction for WAR10 yields a satisfactory fit to the experimental data.

respect to the crystallographic directions was determined from the position of the ${ }^{15} \mathrm{~N}_{\mathrm{S}}^{0}$ EPR lines.

In a ${ }^{14} \mathrm{~N}$-doped sample the central transition of the $\mathrm{N}_{\mathrm{S}}^{0}$ EPR spectrum with its associated satellites appears in the same field range as the entire WAR9 and WAR10 spectra. Figure 4 shows a simulated EPR spectrum with the magnetic field applied parallel to $\langle 001\rangle$ from approximately $20 \mathrm{ppm}$ of ${ }^{14} \mathrm{~N}_{\mathrm{S}}^{0}$ overlaid on a simulation of the detected concentration of WAR9 and WAR10 but with the hyperfine interaction scaled with the ratio of nuclear Zeeman values for ${ }^{14} \mathrm{~N}$ and ${ }^{15} \mathrm{~N}$ [35]. As can be clearly seen in this figure, the WAR9 and WAR10 signals are almost impossible to separate from the ${ }^{14} \mathrm{~N}_{\mathrm{S}}^{0}$ EPR spectrum, illustrating the importance of isotopical substitution of nitrogen for the detection of these two defects. The WAR9 and WAR10 lines are centred around $g \approx 2.002$ and all found within a $0.5 \mathrm{mT}$ range of fields at X-band and $1.0 \mathrm{mT}$ at Q-band as can be seen in figures 5 and 6 .

No change in the EPR spectrum for WAR9 and WAR10 was detected down to the lowest measured temperature of $10 \mathrm{~K}$. The intensities of the WAR9 and WAR10 EPR 


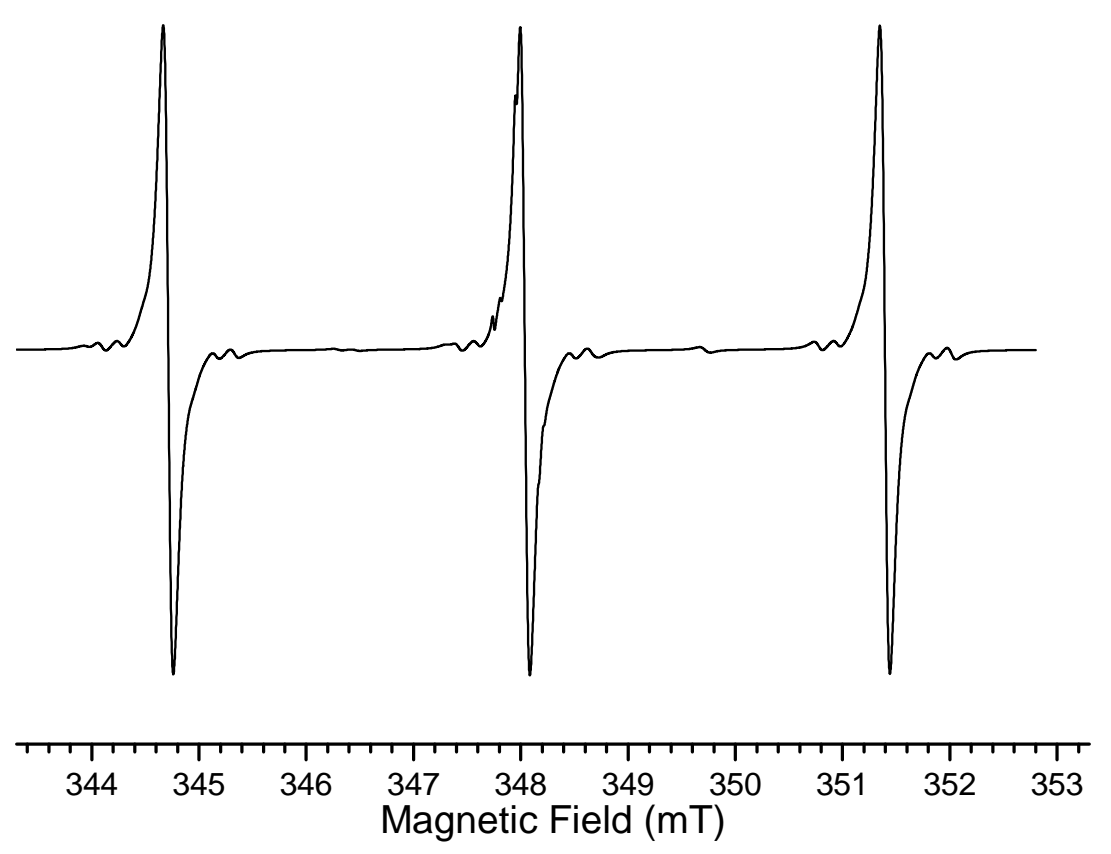

Figure 4. Simulated X-band first derivative EPR spectrum with the magnetic field applied along $\langle 001\rangle$ showing ${ }^{14} \mathrm{~N}_{\mathrm{S}}^{0}$ overlapping with ${ }^{14} \mathrm{~N}$ versions of WAR9 and WAR10. These have been simulated with the ${ }^{15} \mathrm{~N}$ hyperfine interaction multiplied by the ratio of the nuclear Zeeman values for ${ }^{14} \mathrm{~N}$ and ${ }^{15} \mathrm{~N}$ [35]. The quadrupole interaction is set to zero.

signals have not been found to change on annealing the sample up to a temperature of $1800 \mathrm{~K}$.

\section{Analysis of the data}

The X-band EPR spectra from the two new defects were fitted to the spin Hamiltonian

$$
H=\mu_{B} \mathbf{B} \cdot \underline{\mathbf{g}} \cdot \mathbf{S}+\mathbf{S} \cdot \underline{\mathbf{A}} \cdot \mathbf{I}-g_{N} \mu_{N} \mathbf{B} \cdot \mathbf{I}
$$

with an electronic spin $S=\frac{1}{2}$ and nuclear spin $I=\frac{1}{2}$ from a ${ }^{15} \mathrm{~N}$ nucleus, varying the electronic Zeeman interaction, $\underline{\mathbf{g}}$, and the hyperfine interaction, $\underline{\mathbf{A}}$, see table 1 . The WAR9 defect was constrained to have orthorhombic $C_{2 v}$ symmetry and the WAR10 defect was constrained to have a $\{110\}$ mirror plane. Removing these constraints did not significantly improve the quality of fit. The parameters yield an excellent fit to the experimental data for all magnetic field directions for both the X- and Q-band measurements, as can be seen in figures 2, 5 and 6 . The lines in the X-band spectra at $\sim 347.93 \mathrm{mT}$, for all orientations of the magnetic field, are due to the central transition of the ${ }^{14} \mathrm{~N}_{\mathrm{S}}^{0}$ spectrum. This line was used as a $g$-marker and the determined electronic 


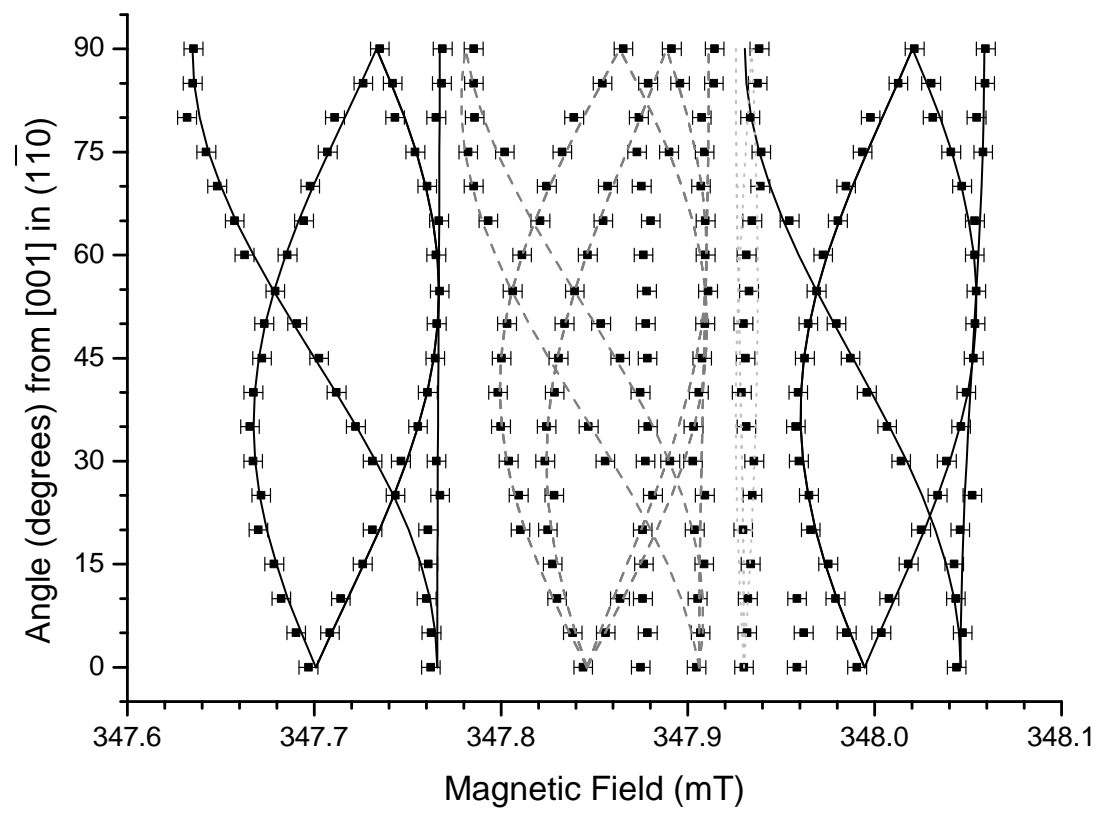

Figure 5. X-band EPR line positions for different orientations of the applied magnetic field in the crystallographic (11̄0) plane. The points ( $)$ represent experimental peak positions and the lines show simulated peak positions for WAR9 as solid lines (-)and WAR10 as dashed lines (- - - ) using the fitted parameters of table 1. The dotted line $(\cdots \cdots)$ shows the position of the central ${ }^{14} \mathrm{~N}_{\mathrm{S}}^{0}$ peak, see also figure 2 .

Table 1. Spin Hamiltonian parameters for the two new ${ }^{15} \mathrm{~N}$ containing defects with directions $[\theta, \varphi]$, where $\theta$ is the angle from the crystallographic [001] direction and $\varphi$ is the angle from [100] measured towards [010] in the (100) plane.

\begin{tabular}{llll}
\hline Defect & $\mathbf{g}_{1}$ & $\mathbf{g}_{2}$ & $\mathbf{g}_{3}$ \\
\hline WAR9 & $2.00343(10) \|\left[90^{\circ}, 45^{\circ}\right]$ & $2.00272(10) \|\left[180^{\circ}, 45^{\circ}\right]$ & $2.00268(10) \|\left[90^{\circ}, 315^{\circ}\right]$ \\
WAR10 & $2.00344(10) \|\left[90.1(2)^{\circ}, 45.0(2)^{\circ}\right]$ & $2.00272(10) \|\left[179.9(2)^{\circ}, 45.0(2)^{\circ}\right]$ & $2.00269(10) \|\left[90^{\circ}, 315^{\circ}\right]$ \\
\hline & $\mathbf{A}_{1} / \mathbf{M H z}$ & $\mathbf{A}_{2} / \mathbf{M H z}$ & $\mathbf{A}_{3} / \mathbf{M H z}$ \\
\hline WAR9 & $8.30(5) \|\left[90^{\circ}, 45^{\circ}\right]$ & $7.85(5) \|\left[180^{\circ}, 45^{\circ}\right]$ & $8.17(5) \|\left[90^{\circ}, 315^{\circ}\right]$ \\
WAR10 & $1.00(4) \|\left[44.8(3)^{\circ}, 45.0(7)^{\circ}\right]$ & $-1.01(4) \|\left[134.8(3)^{\circ}, 45.0(7)^{\circ}\right]$ & $0.00(4) \|\left[90^{\circ}, 315^{\circ}\right]$ \\
\hline
\end{tabular}

Zeeman parameters are referenced to its literature g-value of 2.0024(5) [34].

It is possible to achieve an equally good fit to the experimental WAR10 line positions at X-band using a spin Hamiltonian with only an electronic Zeeman interaction with $C_{1 h}$ symmetry keeping only the $\{110\}$ mirror plane. However, this does not yield a satisfactory fit to the Q-band data. This is illustrated in figure 3 which shows the experimental Q-band spectrum recorded with the magnetic field parallel to $\langle 111\rangle$ together with two different simulated spectra: the top one is simulated using the spin Hamiltonian parameters of table 1 and the bottom one using the parameters obtained 


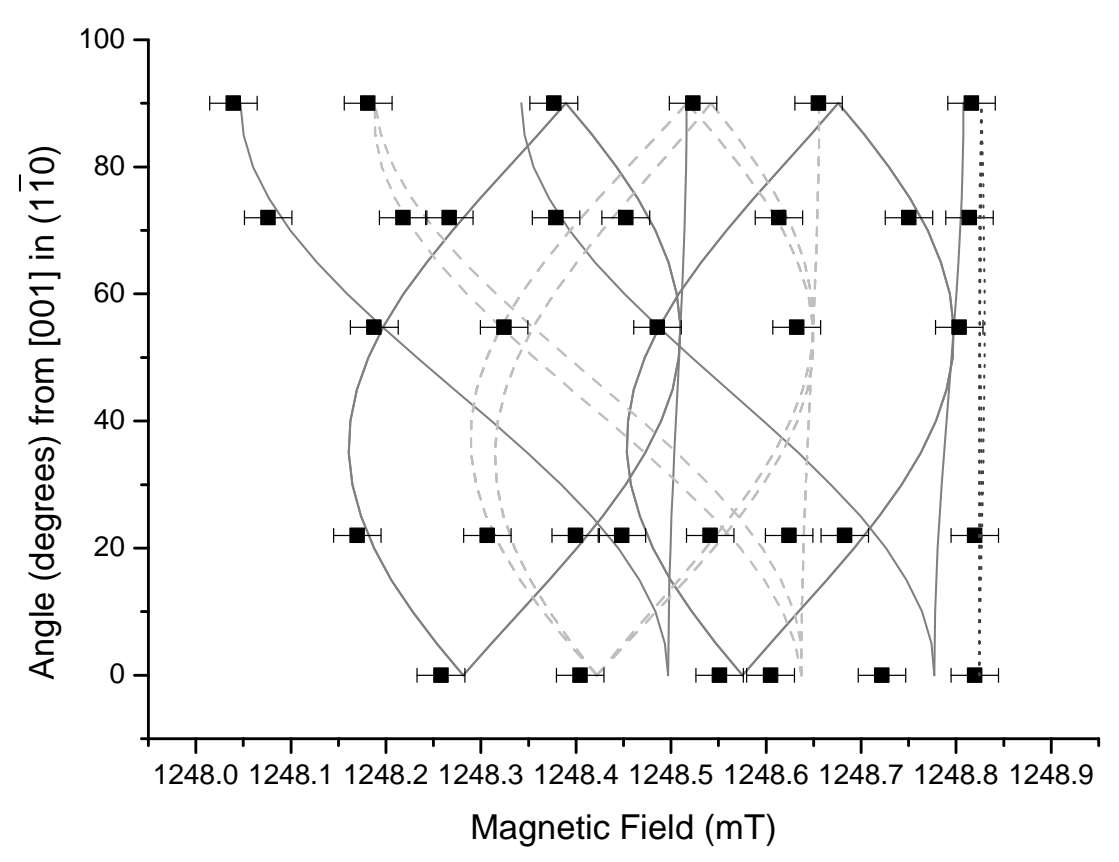

Figure 6. Q-band EPR line positions for different orientations of the applied magnetic field in the crystallographic (11̄0) plane. The points ( $)$ represent experimental peak positions and the lines show simulated peak positions for WAR9 as solid lines (- - and WAR10 as dashed lines (- - - ) using the fitted parameters of table 1. The dotted line $(\cdots \cdots)$ shows the position of the central ${ }^{14} \mathrm{~N}_{\mathrm{S}}^{0}$ peak.

when fitting the X-band WAR10 line positions assuming $C_{1 h}$ symmetry and only an anisotropic electronic Zeeman interaction. Only the simulation involving a hyperfine interaction with ${ }^{15} \mathrm{~N}$ fits both the Q-band and X-band data, see also figure 2. The hyperfine interaction is assumed to be with a ${ }^{15} \mathrm{~N}$ nucleus for both WAR9 and WAR10 since this is the only $\sim 100 \%$ abundant $I=\frac{1}{2}$ nucleus in this sample.

\section{Discussion}

As can be seen in table 1 the two new defects have identical electronic Zeeman parameters, with orthorhombic symmetry and a $\langle 110\rangle C_{2 v}$ symmetry axis. The hyperfine interactions, on the other hand, are very different: For WAR9 the hyperfine interaction has the same $\langle 110\rangle C_{2 v}$ symmetry axis as the electronic Zeeman interaction and small anisotropy, while the hyperfine interaction in WAR10 has an isotropic component that is approximately zero and the symmetry is lowered to $C_{1 h}$, keeping the $\{110\}$ mirror plane.

The WAR9 and WAR10 EPR spectra are detected after electron irradiation and annealing to $1100 \mathrm{~K}$. However, since the EPR signal from negatively charged isolated vacancies [6] appears in the same region of the spectrum as WAR9 and WAR10, see 
figure 1b) these defects would not be detected until the vacancies have been annealed out. There are therefore several possibilities for when the WAR9 and WAR10 defects are formed: The centres could be formed directly after the irradiation, which could provide an explanation for the fact that in samples containing $N_{S}$ no $R 1$ is formed on electron irradiation [26]: WAR9 and WAR10 are formed instead. Another possibility is that WAR9 and WAR10 are formed after annealing at some temperature $<1100 \mathrm{~K}$, the annealing temperature used in this study. For example, the isolated, neutral $\langle 100\rangle$-split self-interstitial $\left(\mathrm{I}_{001}\right)$ giving rise to the R2 EPR spectrum is stable up to $700 \mathrm{~K}[10,36]$. The WAR9 and WAR10 defects could be formed as $\mathrm{I}_{001}$ becomes mobile. It is of course also possible that these defects are only formed at the temperature the sample was annealed at. They would in any case not be detectable before the $\mathrm{V}^{-}$EPR signal has disappeared from the spectrum.

\subsection{Model for WAR9}

For the $\langle 001\rangle$-split nitrogen interstitial, $\mathrm{N}_{\mathrm{I}}$, illustrated in figure $7 \mathrm{~b}$, we expect $C_{2 v}$ symmetry and inclusion of one nitrogen atom and that it is formed after irradiation and possibly annealing. This defect should be EPR active with $S=\frac{1}{2}$ in the neutral charge state. The $\langle 001\rangle$-split nitrogen interstitial model is an analog of the $(\mathrm{N}-\mathrm{B})_{i}^{+}$defect which gives rise to the EPR spectrum labelled NIRIM-4 [37]. In this centre the majority of the unpaired electron density is localised on the nitrogen atom with a minor amount on the boron; for $\mathrm{N}_{\mathrm{I}}$ we expect to have a filled $\mathrm{p}_{\pi}$ orbital on the nitrogen atom and a half-filled $\mathrm{p}_{\pi}$ orbital on the carbon atom, so that the majority of the unpaired electron probability density is localised on the carbon atom. Scaling the magnitude of the ${ }^{11} \mathrm{~B}$ hyperfine interaction for NIRIM-4 [37] with the ratio of the ${ }^{11} \mathrm{~B}$ to ${ }^{15} \mathrm{~N}$ nuclear Zeeman values [35], we get $\left|\mathrm{A}_{1}\right|=13.5 \mathrm{MHz},\left|\mathrm{A}_{2}\right|=10.4 \mathrm{MHz}$ and $\left|\mathrm{A}_{3}\right|=7.9 \mathrm{MHz}$. The WAR9 defect has

the required $C_{2 v}$ symmetry and the right $S=\frac{1}{2}$ spin to be the neutral charge state of $\mathrm{N}_{\mathrm{I}}$. The measured ${ }^{15} \mathrm{~N}$ hyperfine values for WAR9 of approximately $8 \mathrm{MHz}$, see table 1 , are also in reasonable agreement with those calculated from comparison with the NIRIM-4 centre. $\mathrm{N}_{\mathrm{I}}^{0}$ is therefore a possible model for the WAR9 defect.

If the $\mathrm{N}_{\mathrm{S}}^{0}$ is sufficiently high, the $\mathrm{N}_{\mathrm{I}}$ may accept an electron from $\mathrm{N}_{\mathrm{S}}^{0}$ and become diamagnetic. The WAR9 spectrum has a narrow line width meaning that the signal comes from the low $\mathrm{N}_{\mathrm{S}}$ regions of the sample. In the high $\mathrm{N}_{\mathrm{S}}$ sectors we expect $\mathrm{N}_{\mathrm{I}}$ to be in the negative charge state, which would be diamagnetic (as well as having broader EPR lines). If Goss et al.'s [27] model of the H1a IR centre [28] as a di-nitrogen interstitial, $\mathrm{N}_{2 \mathrm{I}}$, is correct its likely formation mechanism in Type Ib diamond is trapping of $\mathrm{N}_{\mathrm{I}}$ by $\mathrm{N}_{\mathrm{S}}$. Since H1a is formed on annealing at $950 \mathrm{~K}$ in Type Ib material, this suggests that the nitrogen interstitial is mobile at this temperature in the negative charge state. The neutral charge state of $\mathrm{N}_{\mathrm{I}}$ may have a much higher thermal stability so that this does not rule out the assignment of WAR9 to $\mathrm{N}_{\mathrm{I}}$. 


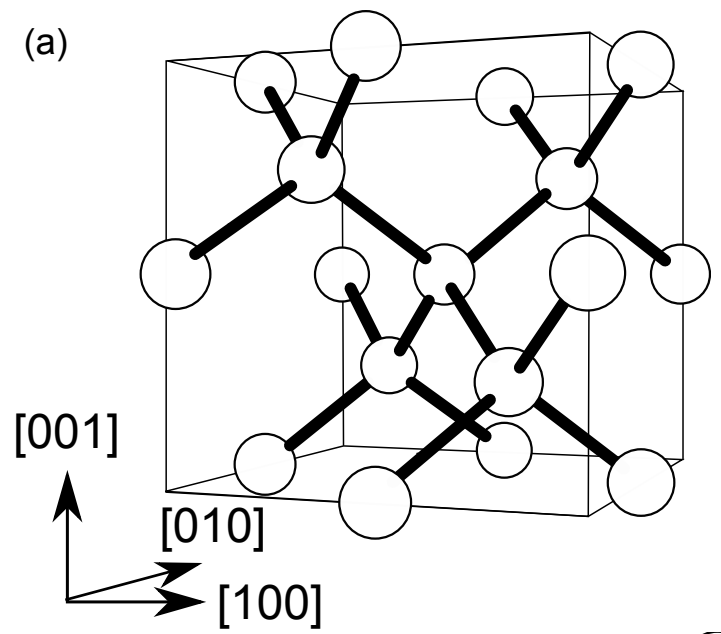

(b)

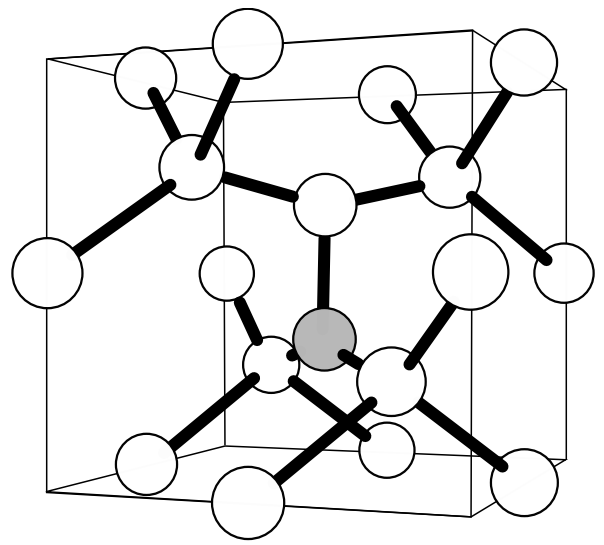

(c)

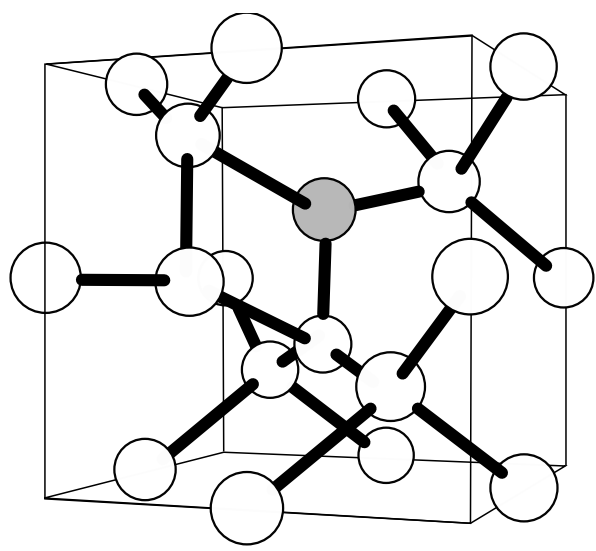

Figure 7. Models of the diamond lattice adapted from the paper by Goss et al. [11]. The unfilled circles are carbon atoms and the filled circles are nitrogen atoms. (a) shows the undistorted diamond lattice, (b) shows a $\langle 100\rangle$-split nitrogen interstitial, $\mathrm{N}_{\mathrm{I}}$, and (c) shows a nitrogen interstitial - self-interstitial pair, $\mathrm{N}_{\mathrm{I}}-\mathrm{I}_{001}$.

\subsection{Model for WAR10}

For a nearest neighbour $\langle 001\rangle$-split nitrogen interstitial - self interstitial pair, $\mathrm{N}_{\mathrm{I}}-\mathrm{I}_{001}$, see figure $7 \mathrm{c}$, in the neutral charge state we expect, as for $\mathrm{N}_{\mathrm{I}}$, a filled $\mathrm{p}_{\pi}$ orbital on the nitrogen atom and a half-filled $\mathrm{p}_{\pi}$ orbital on the carbon atom, yielding a defect with $C_{1 h}$ symmetry and an $S=\frac{1}{2}$ ground state.

If we view the $\mathrm{N}_{\mathrm{I}}-\mathrm{I}_{001}$ defect as analogous to the R1 EPR centre it is possible to estimate the hyperfine interaction from a simple dipole-dipole calculation between the unpaired electron probability density and the nitrogen nucleus. The inter-radical distance of the $\mathrm{R} 1$ centre has been calculated to be $1.7 \AA$ [11], so we set this to be the distance between the $\mathrm{N}$-atom and the $\mathrm{C}$-atom with the partially filled $\mathrm{p}_{\pi}$ orbital. From the ${ }^{13} \mathrm{C}$ hyperfine interaction in the $\mathrm{R} 1$ centre it has been estimated that approximately $70 \%$ of the unpaired electron probability density is in the partially filled $\mathrm{p}_{\pi}$ orbitals. Following Hunt et al. [10] we therefore assume $35 \%$ of the unpaired electron probability 
density to be centred a distance $\mathrm{X}=0.6 \AA$ on either side of the $\mathrm{C}$-nucleus along the [110] direction. This yields two contributions to the hyperfine interaction which were transformed to a common coordinate axes system and summed. The principal values of this hyperfine tensor are $A_{1}=1.6 \mathrm{MHz}, A_{2}=-1.0 \mathrm{MHz}$ and $A_{3}=-0.6 \mathrm{MHz}$ with

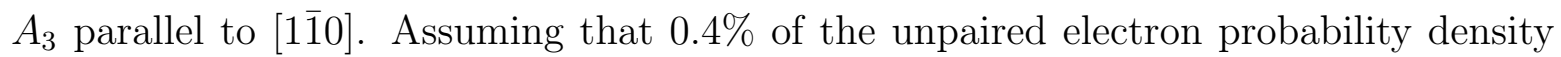
is localised on the N-atom yields an additional uniaxial hyperfine contribution of the form $A_{\|}=-2 b$ and $A_{\perp}=b$ with $b=-0.3 \mathrm{MHz}$ and $A_{\|}$along [11̄0]. Adding this to the hyperfine tensor from the electron dipole calculation results in a calculated hyperfine tensor with $A_{1}=-A_{2}=1.3 \mathrm{MHz}$ and $A_{3}=0 \mathrm{MHz}$, with $A_{3}$ still parallel to [110]. This is the form and magnitude of the experimentally determined hyperfine interaction for WAR10, which also has the required $S=\frac{1}{2}$ spin state. The numerical values in the hyperfine calculation are very sensitive to the angle of the interaction, which is determined by the assumed $\mathrm{C}-\mathrm{N}$ distance and position of the unpaired electron probability density along the $\mathrm{p}_{\pi}$-orbital. The good numerical agreement between the calculated and experimental hyperfine interaction should therefore be viewed as fortuitous, but this calculation shows that a $\mathrm{N}_{\mathrm{I}}-\mathrm{I}_{001}$ model in the neutral charge state for WAR10 is consistent with the form of the hyperfine interaction.

As for WAR9 the narrow EPR line width for WAR10 shows that it is only present in the low $\mathrm{N}_{\mathrm{S}}$ sectors. If $\mathrm{N}_{\mathrm{I}}-\mathrm{I}_{001}$ were present in in the high $\mathrm{N}_{\mathrm{S}}$ sectors it probably wouldn't be detectable since in these regions it would be in the negative charge state and therefore diamagnetic. Since $\mathrm{N}_{\mathrm{I}}^{-}$is mobile below the temperatures the sample has been annealed at $\mathrm{N}_{\mathrm{I}}-\mathrm{I}_{001}$ may not be present in the high $\mathrm{N}_{\mathrm{S}}$ sectors at all.

\section{Conclusions}

We have discovered two new nitrogen-containing EPR-active defects in irradiated and annealed diamond, which we label WAR9 and WAR10. We demonstrate that the formation of these defects after electron-irradiation and annealing and their spin-Hamiltonian parameters are consistent with them being the [100]-nitrogen split interstitial $\left(\mathrm{N}_{\mathrm{I}}\right)$ and the $\mathrm{N}_{\mathrm{I}}-\langle 001\rangle$ carbon interstitial pair $\left(\mathrm{N}_{\mathrm{I}}-\mathrm{I}_{001}\right)$, respectively, both in the neutral charge state. The use of an isotopically enriched sample, where $>95 \%$ of the nitrogen was of the ${ }^{15} \mathrm{~N}$ isotope, was the key to detecting these defects, since their EPR spectra overlap with the central transition of the ${ }^{14} \mathrm{~N}_{\mathrm{S}}^{0} \mathrm{EPR}$ spectrum. The narrow line widths of WAR9 and WAR10 indicate that they are only present in the low nitrogen regions of the sample, suggesting that both $\mathrm{N}_{\mathrm{I}}$ and $\mathrm{N}_{\mathrm{I}}-\mathrm{I}_{001}$ are electron acceptors and exist in the negative charge state in the presence of $\mathrm{N}_{\mathrm{S}}$. This also means that even though the average bulk concentration of WAR9 and WAR10 is only $\sim 0.1 \mathrm{ppm}$, they are important irradiation products in low nitrogen sectors of diamond, which may only account for a fraction of the whole sample. The assignment of WAR9 and WAR10 to $\mathrm{N}_{\mathrm{I}}$ and $\mathrm{N}_{\mathrm{I}}-\mathrm{I}_{001}$, requires that both are stable to at least $1800 \mathrm{~K}$. Other annealing data suggests that $\mathrm{N}_{\mathrm{I}}^{-}$is much more mobile and has not survived annealing to $1800 \mathrm{~K}$. The difference in mobility of $\mathrm{N}_{\mathrm{I}}^{0}$ and $\mathrm{N}_{\mathrm{I}}^{-}$was suggested by theory [27]. Nevertheless at first 
sight the survival of $\mathrm{N}_{\mathrm{I}}^{0}$ and $\left[\mathrm{N}_{\mathrm{I}}-\mathrm{I}_{001}\right]^{0}$ is surprising. However, in the low nitrogen sectors $\mathrm{N}_{\mathrm{I}}^{0}$ may be mobile but not able to find a trap at $1800 \mathrm{~K}$.

Further work is required on both the annealing of $\mathrm{N}_{\mathrm{I}}^{0}$ and $\left[\mathrm{N}_{\mathrm{I}}-\mathrm{I}_{001}\right]^{0}$, as well as determining the fraction of nitrogen which can be tied up in interstitial complexes; our results suggest that they are not necessarily minor players and should be considered when using ion implantation to produce useful colour centres in diamond (e.g. $\mathrm{NV}^{-}$).

\section{Acknowledgments}

The authors thank Dr. Joh Hansen of E6 Ltd. for the synthesis of the sample.

\section{References}

[1] G. Davies and E. C. Lightowlers. Symmetry properties of ND1 absorption centre in electronirradiated diamond. J. Phys. C: Solid State Phys., 3(3):638-650, 1970.

[2] C. D. Clark and J. Walker. The neutral vacancy in diamond. Proc. Roy. Soc. Lond. A Mat., 334(1597):241-257, 1973.

[3] G. Davies and C. M. Penchina. Effect of uniaxial stress on GR1 doublet in diamond. Proc. Roy. Soc. Lond. A Mat., 338(1614):359-374, 1974.

[4] G. Davies. Charge states of vacancy in diamond. Nature, 269(5628):498-500, 1977.

[5] G. Davies and C. Foy. Jahn-Teller coupling at the neutral vacancy in diamond. J. Phys. C: Solid State Phys., 13(11):2203-2213, 1980.

[6] J. Isoya, H. Kanda, Y. Uchida, S. C. Lawson, S. Yamasaki, H. Itoh, and Y. Morita. EPR identification of the negatively charged vacancy in diamond. Phys. Rev. B, 45(3):1436, 1992.

[7] J. A. van Wyk, O. D. Tucker, M. E. Newton, J. M. Baker, G. S. Woods, and P. Spear. Magneticresonance measurements on the ${ }^{5} A_{2}$ excited-state of the neutral vacancy in diamond. Phys. Rev. B., 52(17):12657-12667, 1995.

[8] Gordon Davies, Simon C. Lawson, Alan T. Collins, Alison Mainwood, and Sarah J. Sharp. Vacancy-related centers in diamond. Phys. Rev. B., 46(20):13157, 1992.

[9] D. J. Twitchen, M. E. Newton, J. M. Baker, W. F. Banholzer, and T. Anthony. Optical spin polarization in the di-<001>-split interstitial (R1) centre in diamond. Diam. Relat. Mater., 8(6):1101-1106, 1999.

[10] D. C. Hunt, D. J. Twitchen, M. E. Newton, J. M. Baker, T. R. Anthony, W. F. Banholzer, and S. S. Vagarali. Identification of the neutral carbon $<100>$-split interstitial in diamond. Phys. Rev. B, 61(6):3863, 2000.

[11] J. P. Goss, B. J. Coomer, R. Jones, T. D. Shaw, P. R. Briddon, M. Rayson, and S. Öberg. Self-interstitial aggregation in diamond. Phys. Rev. B, 63(19):195208, 2001.

[12] G. Davies, H. Smith, and H. Kanda. Self-interstitial in diamond. Phys. Rev. B, 62(3):1528-1531, 2000 .

[13] M. E. Newton, B. A. Campbell, D. J. Twitchen, J. M. Baker, and T. R. Anthony. Recombinationenhanced diffusion of self-interstitial atoms and vacancy-interstitial recombination in diamond. Diam. Relat. Mater., 11(3-6):618-622, 2002.

[14] D. J. Twitchen, M. E. Newton, J. M. Baker, O. D. Tucker, T. R. Anthony, and W. F. Banholzer. Electron-paramagnetic-resonance measurements on the di- $<001>$-split interstitial center (R1) in diamond. Phys. Rev. B, 54(10):6988-6998, 1996.

[15] Lars Allers, Alan T. Collins, and Jonathan Hiscock. The annealing of interstitial-related optical centres in type II natural and CVD diamond. Diam. Relat. Mater., 7(2-5):228-232, 1998.

[16] D. C. Hunt, D. J. Twitchen, M. E. Newton, J. M. Baker, J. K. Kirui, J. A. van Wyk, T. R. Anthony, 
and W. F. Banholzer. EPR data on the self-interstitial complex O3 in diamond. Phys. Rev. B, 62(10):6587, 2000.

[17] I. Kiflawi and S. C. Lawson. Aggregates of nitrogen in diamond. In M. H. Nazare and A. J. Neves, editors, The Properties, Growth and Application of Diamond, volume 26 of EMIS Datareview Series, pages 130-133. INSPEC, the Institution of Electrical Engineers, London, 2001.

[18] S. Felton, A. M. Edmonds, M. E. Newton, P. M. Martineau, D. Fisher, and D. J. Twitchen. Electron paramagnetic resonance studies of the neutral nitrogen vacancy in diamond. Phys. Rev. B, 77(4):081201(R), 2008.

[19] S. Felton, A. M. Edmonds, M. E. Newton, P. M. Martineau, D. Fisher, D. J. Twitchen, and J. M. Baker. Hyperfine interaction in the ground state of the negatively charged nitrogen vacancy center in diamond. Phys. Rev. B, 79(7):075203-8, 2009.

[20] S. C. Lawson, G. Davies, A. T. Collins, and A. Mainwood. The H2 optical-transition in diamond - the effects of uniaxial-stress perturbations, temperature and isotopic-substitution. J. Phys.: Condens. Matter, 4(13):3439-3452, 1992.

[21] Y. Mita, Y. Nisida, K. Suito, A. Onodera, and S. Yazu. Photochromism of H2 and H3 centers in synthetic type Ib diamonds. J. Phys.: Condens. Matter, 2(43):8567-8574, 1990.

[22] A. T. Collins. Things we still don't know about optical centres in diamond. Diam. Relat. Mater., 8(8-9):1455-1462, 1999.

[23] A. T. Collins, A. Connor, C. H. Ly, A. Shareef, and P. M. Spear. High-temperature annealing of optical centers in type-I diamond. J. Appl. Phys., 97(8):083517, 2005.

[24] A. T. Collins. Vacancy enhanced aggregation of nitrogen in diamond. J. Phys. C: Solid State Phys., 13(14):2641-2650, 1980.

[25] A. T. Collins, H. Kanda, and H. Kitawaki. Colour changes produced in natural brown diamonds by high-pressure, high-temperature treatment. Diam. Relat. Mater., 9(2):113-122, 2000.

[26] G. A. Watt, M. E. Newton, and J. M. Baker. EPR and optical imaging of the growth-sector dependence of radiation-damage defect production in synthetic diamond. Diam. Relat. Mater., 10(9-10):1681-1683, 2001.

[27] J. P. Goss, P. R. Briddon, S. Papagiannidis, and R. Jones. Interstitial nitrogen and its complexes in diamond. Phys. Rev. B, 70(23):235208, 2004.

[28] G. S. Woods and A. T. Collins. The $1450 \mathrm{~cm}^{-1}$ infrared-absorption in annealed, electron-irradiated type-I diamonds. J. Phys. C: Solid State Phys., 15(26):L949-L952, 1982.

[29] R. C. Burns, V. Cvetkovic, C. N. Dodge, D. J. F. Evans, M. L. T. Rooney, P. M. Spear, and C. M. Welbourn. Growth-sector dependence of optical-features in large synthetic diamonds. J. Cryst. Growth, 104(2):257-279, 1990.

[30] Corina Vera Helga Stroemann, Francis Tshisikhawe, John Olaf Hansen, and Robert Charles Burns. International Patent Application: WO2006061672 (15/06/2006).

[31] T. Evans and Z. Qi. The kinetics of the aggregation of nitrogen-atoms in diamond. Proc. Roy. Soc. Lond. A Mat., 381(1780):159-178, 1982.

[32] Trevor Evans. Aggregation of nitrogen in diamond. In J.E. Field, editor, The Properties of Natural and Synthetic Diamond, pages 259-290. Academic Press Limited, London, 1992.

[33] J. A. van Wyk, E. C. Reynhardt, G. L. High, and I. Kiflawi. The dependences of ESR line widths and spin - spin relaxation times of single nitrogen defects on the concentration of nitrogen defects in diamond. Journal of Physics D: Applied Physics, (12):1790, 1997.

[34] W. V. Smith, P. P. Sorokin, I. L. Gelles, and G. J. Lasher. Electron-spin resonance of nitrogen donors in diamond. Phys. Rev., 115(6):1546, 1959.

[35] David R. Lide. CRC handbook of chemistry and physics. CRC Press, Boca Raton, FL, 87th edition, 2006.

[36] A. T. Collins and A. Dahwich. The annealing of interstitial-related optical centres in type Ib diamond. Diam. Relat. Mater., 13(11-12):1959-1962, 2004.

[37] J. Isoya, H. Kanda, and Y. Morita. EPR identification of the $<001>$-split $[\mathrm{B}-\mathrm{N}]^{+}$interstitialcy in diamond. Phys. Rev. B, 56(11):6392, 1997. 